\title{
EU SABO PORQUE SABO: A POÉTICA DA IMPROVISAÇÃO NA EDUCAÇÃO MUSICAL
}

\author{
I know cos I know: the poetics of \\ improvisation in musical education
}

\author{
Yo Sé Porque Sé: la poética de la \\ improvisación en la educación musical
}

\author{
DULCIMARTA LEMOS LINO \\ Universidade Federal do Rio Grande do Sul \\ dulcimartalino@gmail.com
}

GABRIEL DO NASCIMENTO DORNELLES

Universidade Federal do Rio Grande do Sul gabriel.dornelles@maristas.org.br

\begin{abstract}
Resumo: O artigo apresenta o movimento provocado pela prática criativa da improvisação na formação de professores. Como abordagem metodológica qualitativa da pesquisa de campo "Educação Musical na formação de professores dos cursos de Graduação em Pedagogia gaúchos", o Ateliê Poético é espaço propositivo de viver a improvisação para colher as práticas experimentadas na universidade em educação musical. Espaço de articulação da potência lúdica de tocar nossos sentidos de habitar a linguagem, colocando a música em estado de encontro. Os resultados destacam a relevância da improvisação no fluxo inato de sentir e dar sentido à experiência de brincar com sons. A improvisação ensina o corpo a aprender de ouvido e inventar modos de tocar no coletivo, porque prepara e ensaia o inesperado: ação fundante do saber docente. A poética da improvisação na educação musical pode aproximar e intensificar os processos lúdicos de escuta e criação para interrogar a docência de música com crianças.
\end{abstract}

Palavras-chave: Improvisação musical. Educação musical. Práticas criativas em educação musical.

\begin{abstract}
This article presents the movement generated by the poetics of improvisation in teacher's qualification in Musical Education. Composed by university students, educators and musicians, the Poetic Atelier is a methodological approach constituted in Pedagogy Course to indicate current practices in Musical Education; it is a experiencing and improvisation space to articulate the potentialities of the playful spirit that touches our senses and dwells within language. The Atelier is interested in forms that cannot be discussed, but experienced, putting music in a state of confluence. The results highlight the relevance of improvisation in the inner flow of feeling and making sense of the experience of playing with sounds. As it is an essentially collective and everyday activity, improvisation prepares and rehearses the unexpected, educating to exploration and negotiation of other forms of personal relationships that are not based on hierarchy and competition. The act of improvising can approximate and intensify the playful processes of listening and creation, possibilities for conversation and exercise of teacher's knowledge.
\end{abstract}

Keywords: Musical Improvisation. Musical Education. Pedagogy.

Resumen: El artículo presenta el movimiento causado por la práctica de improvisación creativa en la formación de los docentes. Como enfoque metodológico cualitativo de la investigación de campo Educación Musical en la Formación de Profesores de Pregrado en Pedagogía Gaucha, el Taller Poetico es espacio proposicional para vivir la improvisación y recoger las prácticas experimentadas en la Universidad en educación musical. Espacio de articulación de energía lúdica a tocar nuestros sentidos que habitan el lenguaje, poner la música en un estado de encuentro. Los resultados destacan la importancia de la improvisación en el flujo innato de sentir y dar sentido a la experiencia de jugar con los sonidos. La improvisación enseña al cuerpo a aprender de oído e inventar modos de tocar en grupo, porque prepara y ensaya lo inesperado: acción fundacional del saber docente. La poética de la improvisación en la educación musical puede atraer e intensificar los procesos lúdicos de escucha y de creación para interrogar la enseñanza de la música en los niños.

Palabras clave: la improvisación musical; la educación musical; licenciatura en pedagogía. 


\section{INTRODUÇÃO}

O presente artigo tem como objetivo apresentar alguns dos movimentos provocados pela temática da improvisação na pesquisa ${ }^{1}$ que viemos desenvolvendo na universidade. $O$ recorte aqui tomado narra parte qualitativa da extensa pesquisa de campo que tem investigado a formação de professores em educação musical (Lino, 2017). O encontro com acadêmicos da Licenciatura em Pedagogia no Ateliê Poético teve, na improvisação, a prática criativa, que aproximou e intensificou a experimentação dos processos de escuta e criação para interrogar a docência de música com crianças.

As investigações de Fonterrada (2015), Gainza (1983) e Alonso (2014) têm indicado que o cotidiano das escolas brasileiras e dos cursos profissionalizantes e superiores de Música dedicam espaço restrito ao estudo e prática da improvisação musical. Nos cursos superiores de Licenciatura em Pedagogia, a realidade não é diferente. Mesmo que diferentes espaços emerjam como resistência (Figueiredo, 2011; Maffioletti, 1998; Belloquio, 2017; Lino, 2011, 2017), garantindo a presença da disciplina de educação musical em seus currículos de formação, todo esse empenho não parece suficiente para assegurar a presença da prática criativa da improvisação no processo de formação de professores unidocentes.

A temática da educação musical e unidocência foi intensamente desenvolvida no livro de Belloquio (2017) e seus colaboradores. No cenário gaúcho, as contribuições do Fapem/UFSM ${ }^{2}$ têm evidenciado a presença ainda marginal da música na formação de professores unidocentes e mobilizado problematizações no sentido da qualificação dessa formação. Ao definir unidocência "como uma prática do professor de referência que desenvolve sua atividade profissional junto a crianças pequenas, potencializando com elas [...] as primeiras incursões sistematizadas de conceitos básicos musicais" (Bellochio, 2017, p. 171), esses investigadores apontam a necessidade urgente de investimento em cursos e seminários extensivos para que as técnicas e metodologias ligadas às práticas criativas possam se ampliar e consolidar em todo o país.

O Ateliê Poético que propusemos na presente investigação (Lino, 2017) evidencia uma tentativa de ampliar a pesquisa no campo da educação musical, na especificidade da formação de professores da educação infantil. Ao se constituir como abordagem metodológica qualitativa da pesquisa de campo "Educação musical na formação de professores dos cursos de Licenciatura em Pedagogia gaúchos” (Lino, 2017-2020), o Ateliê Poético surge

\footnotetext{
1 Educação Musical na formação de professores dos Cursos de Graduação em Pedagogia Gaúchos: processos de escuta e criação na experiência de barulhar (Lino, 2017-2020).

2 Grupo de Estudos "Formação, Ação e Pesquisa em Educação Musical", da Universidade Federal de Santa Maria.
} 
para complementar a totalidade do fenômeno investigado, identificando os "referentes da ação docente presentes nos bancos universitários" (Gatti; Silv; Almeida, 2016, p. 288). Assim, a improvisação é experimentada no Ateliê Poético com o objetivo de conhecer a educação musical constituída na universidade.

Desde 2017, as universidades vêm buscando constituir a formalização das Diretrizes Curriculares Nacionais para os cursos de Licenciatura em Pedagogia (Brasil, 2015) na particularidade dos sistemas de educação locais. Um impasse político, econômico e ideológico que se impõe frente aos colegiados, na manutenção e ampliação de carga horária suficiente para contemplar, na formação dos futuros pedagogos, o direito à educação musical. Após alcançar tal propósito, ainda experimentamos organizar a súmula e o plano de ensino da disciplina para compor, na pequena carga horária disponível (obrigatória ou eletiva), os objetivos e conteúdos mínimos a trabalhar. Tempo de fazer escolhas e contemplar a prática criativa da improvisação com o objetivo de oferecer aos acadêmicos ferramentas múltiplas e plurais para enfrentar os desafios urgentes que a educação contemporânea exige.

Além disso, o currículo homologado à educação infantil na Base Nacional Comum Curricular (Brasil, 2017), mesmo após a interrupção de um processo cooperativo e dialógico desencadeado em suas duas primeiras versões, que desloca alguns princípios em sua versão final, incorpora importantes conquistas. Ao romper com as divisões tradicionais da organização curricular, outrora estruturada em áreas de conhecimento e componentes curriculares, a atual proposição da BNCC (Brasil, 2017) demanda um educador musical conectado ao conceito de infância e linguagem, porque organizada em Campos de Experiência e Direitos de Aprendizagem. Logo, a música emerge como prática educativa que necessita abdicar da lista de conteúdos e atividades prescritivas a desenvolver (características da disciplina) para tomar como eixo estruturante do fazer cotidiano a criança como um ser integral que se relaciona com o mundo a partir de seu corpo e das interações e brincadeiras que experimenta no currículo (Brasil, 2009).

Nesse cenário, investigar a prática criativa da improvisação na formação de professores em educação musical pode aproximar e ensaiar habilidades urgentes para "acolher as situações e as experiências concretas da vida cotidiana das crianças e seus saberes, entrelaçando-os aos conhecimentos que fazem parte do patrimônio artístico e cultural" (Brasil, 2017 , p. 38). O artigo aproxima reflexões experimentadas ao colocar a música em estado de encontro no Ateliê Poético, espaço propositivo de viver a improvisação. Encontro como disponibilidade para tocar, escutar, estar, entrar em sintonia com o outro. Abertura de um tempo-espaço brincante que, ao improvisar, busca palavras em que seja possivel reiterar, uma ou outra vez, a interrogação: por que educação musical? 


\section{“EU SABO PORQUE SABO!”}

Ao tentar circunscrever o conceito de improvisação, todas as tentativas parecem irrelevantes à afirmação de Vavá: "Oh menina, como sabes tocar assim? [Vavá fita a professora em silêncio, direciona o olhar e as mãos para o 'paneleiro' que toca e afirma: Eu sabo porque sabo! Eu que me ensinei!" (Lino, 2017, p. 2). A improvisação ressoa este estar preparado que a menina de quatro anos declara. Mesmo que sempre em processo, a improvisação é essa prática lúdica e criativa que envolve uma relação fluída com os outros (grupo e/ou instrumento). Um saber e fazer que ensina o corpo a se expor. A improvisação parte da realidade, habita a fronteira entre o sonoro e o musical, cria conexões entre as necessidades expressivas e a técnica instrumental. Na improvisação, o importante é ressoar uma fluidez brincante, exercitando-se publicamente e adquirindo as ferramentas características do jogo no acontecer poético. Ao negar seu caráter espontaneísta, a improvisação exige uma relação coletiva e cotidiana do corpo lançado à sensibilidade de soar, que toma decisões via linguagem, inventando e/ou se apropriando de um "modo de fazer" no instante imprevisivel e inesperado de tocar.

A palavra improvisar vem do latim: em e provisus, de providere, que significa ver antecipadamente, previamente (Petruchelli, 1998, p. 18). Para Gainza (1983), a improvisação é "uma atividade projetiva que pode definir-se como toda execução musical instantânea produzida por um indivíduo ou grupo" (Gainza, 1983, p. 11). A pedagoga afirma que o termo improvisação é utilizado tanto para designar a atividade, o ato de tocar, como seu produto, a performance. Um e outro, um no outro, um com o outro.

Sendo uma prática criativa, o estudo da improvisação musical começa a ter destaque na pedagogia musical por volta da década de 1960 (Frega, 1997; Mateiro; Ilari, 2011; Mateiro; Ilari, 2016). Naquele momento, as práticas criativas de improvisação, composição e participação coletiva nos laboratórios e nas oficinas de música, como tempos e espaços de escuta e experimentação sonora, se estabeleceram em diferentes centros investigativos, possibilidade de questionamento e reflexão constante ao ensino de música (Fonterrada, 2008, 2015). Mesmo que em pequena escala, esses diferentes núcleos de estudo se espalharam pelo Brasil, deslocando certezas instituídas à educação musical, porque ofereciam práticas e conceitos ligados ao imaginário criador e à qualificação da performance instrumental.

Na década de 1980, Porto Alegre recebe os alemães Theophil Maier e Hans-Joachim Koellreutter, o canadense Murray Schafer, a argentina Violeta de Gainza e os brasileiros Carlos Kater, Marisa Fonterrada, Cecília Conde e Luiz Carlos Czéko, em diferentes oficinas e seminários, onde as práticas criativas eram vivenciadas, buscando aproximar os estudantes do som, do ruído, do silêncio, da escuta da paisagem sonora, do corpo como 
objeto sonoro e da exploração dos instrumentos musicais tradicionais. Tal postura envolvia uma contínua experimentação que interrogou a educação musical embasada exclusivamente na música do passado, tendo como característica a separação da vida cotidiana e a orientação fixada na formação de instrumentistas (Fonterrada, 2015, p. 17). Impulsionados e acolhidos econômica e teoricamente pela universidade, ramificam-se no território gaúcho diferentes redes de estudo em práticas criativas conectadas à esfera municipal, estadual e nacional.

Unidos pelo enfrentamento ao impulso civilizatório e colonizador instituído e sedimentado, no Rio Grande do Sul, pelo ensino ministrado nos "Conservatórios de Música", as redes de estudo funcionavam como núcleos investigativos interessados em práticas criativas musicais. Neste contexto, a improvisação aparece como uma narrativa de conversação musical possível, porque não se preocupava em demarcar "um território a ser domesticado em uma paisagem que refletia apenas o olho desejante do espectador" (Cage, 2015, p. 39). Ao contrário, o que aprendemos é que "as narrativas que usamos como nossa história principiam em algum sentido potente generativo de futuro" (Cage, 2015, p. 56).

Para o compositor, a improvisação envolve uma conversação, sem tempos verbais ordenados ou modos e estilos determinados, mas que exigem

[...] estar com (con), virar-se (versar) para - ou seja, para fora do eu apenas. O verso da poesia e o verso da conversação estão relacionados apenas dessa forma, como um literal virar-se - na melhor das hipóteses, inesperadamente, em direção aos nossos muitos passados, presente, futuros, isto é, em direção a possibilidades, contingências, reconhecimentos, ininteligibilidades (Cage, 2015, p. 17).

John Cage relata que essa conversação se refere a uma coexistência que muda de um contexto para o outro, tendo como ponto de entrada viver o tempo e lugar real e cotidiano; sempre fragmentado. As obras do compositor foram construídas por meio de "operações de acaso", isto é, "possibilidades de encontro com o desconhecido, de ação e intervenção cotidianas, uma forma de imitar a natureza em seu modo de proceder" (Cage, 2015, p. 12). Ao se interessar por formas que não se podia discutir, mas experimentar, Cage nos convida a tocar o silêncio e o ruído, como possibilidade de escuta. Quem sabe, por essa razão, o compositor se valha de artefatos sonoros não convencionais, como ferramentas para provar os limites e as possibilidades do discurso sonoro que, no ato de improvisar, estão estruturados de uma maneira muito parecida com a vida cotidiana. Um lugar

[...] em que incontáveis, inenarráveis e insustentáveis cruzamentos e justaposições de eventos - alguns deles projetados - a maior parte por acaso - nos deixam atordoados, estupefatos, maravilhados, curiosos, desesperados, confusos [...] paradigmas de intrincadas 
complexidades multidimensionais, interdisciplinares e interculturais que substituem as sondagens verticais de superficialidade e profundidade que têm caracterizado nossas críticas eurocêntricas de julgamento - com a "profundidade" aumentando em proporção à distância do dia a dia (Cage, 2015, p. 55).

Neste contexto, o fazer da improvisação inclui uma multidimensionalidade interdisciplinar de possibilidades que se encontram no próprio ato de tocar o mundo. Além de iniciar uma conversação movimentando o fluxo sonoro e as características que a materialidade nos impõe, a improvisação torna o corpo presente com sua respiração, escuta, técnica. Potência de um devir transformador que resiste, insiste e enfrenta o risco dos limites da materialidade, para conquistar o tempo instantâneo da sintonia, da brincadeira, da conversação.

Como ensaios de deslocamentos, a improvisação pode se tornar composição-música, mas não tem esse compromisso. Seu único encargo ou atribuição é participar da experiência. Ao mobilizar o artesanato da linguagem, a improvisação vibra o ato de "tocar o som, o silêncio, o ruido, a música" nas múltiplas narratividades de línguas disponíveis. Porém, o que de fato o ato de improvisar articula é a potência lúdica de tocar nossos sentidos de habitar a linguagem (Agamben, 2011). Ao criar uma experiência focada na abertura à dissonância e às aleatoriedades, na descontinuidade temporal e/ou na simples manipulação de materialidades (sem interesse em uma performance estilística definida), a improvisação emerge como território de abertura à contradição e à discussão; possibilidade tão instauradora quanto reflexiva da ação poética que, experimentada nos encontros de viver a linguagem, pode marcar seu protagonismo e alteridade (Richter; Berle, 2015).

Ao restituir a importância de brincar com sons na imprevisibilidade do instante, "barulhando" (Lino, 2017), a improvisação interpela a escuta, que vagueia na tentativa vã de apreender a unicidade de cada parte. A improvisação é, pois, um exercício libertário que ensina o corpo a fazer, desenclausurando a compreensão sensivel do mundo porque ato poético. Poética compreendida como nome de tudo que se relaciona com a criação ou a composição de obras em que a linguagem é ao mesmo tempo substância e meio. Desviar da compreensão de improvisação como algo da ordem da espontaneidade é condição indispensável para tomá-la no sentido de uma relação com a realidade, com o mundo, e não como expressão da interioridade do indivíduo.

Vale destacar que só há mundo porque há algo entre aqueles que o têm em comum. Para Arendt, o mundo não pode ser compreendido como morada de um único povo, mas, sim, como morada de uma multiplicidade de etnias e culturas, pois, "quanto mais povos, mais mundo" (Arendt, 2002, p. 37). A filósofa afirma que somos seres no e do mundo, destacando que o mundo é 
a marca indelével de que somos seres que constroem história e cultura (Arendt, 2005, p. 166). O apelo ético arendtiano reside em destacar que o mundo só se torna possivel por sua atividade pública, comum, mundana. Por isso, "conviver no mundo significa essencialmente ter um mundo de coisas interpostas entre os que nele habitam em comum, como uma mesa se interpõe entre os que se assentam em seu redor, pois, como todo intermediário, o mundo ao mesmo tempo separa e estabelece uma relação entre os homens" (Arendt, 2005, p. 62).

O som é mundo e ressoa no corpo a coexistência de um gesto que toma a decisão de iniciar: entrar em linguagem (Agamben, 2011). Então, o mundo é sonoro e musical. Sonoro porque constituido pelo continuum de som, ruído e silêncio que habita o universo, coexistindo na realidade cotidiana, sem fragmentações. E musical porque demarcaçãoda organização de diferentes culturas para fundar um sentido de ordenação do sonoro ao decidir iniciar o gesto de produzir um contexto de pulsações articuladas. Wisnik (1989, p. 32) destaca que "produzir a sociedade significa atentar contra o universo, recortar o que é uno, tornar discreto o que é contínuo". Criar música é, pois, a narratividade poética, que através do tempo e das culturas acolhe e/ou rejeita o mundo. Isso porque a música incorpora o movimento cadencial de tensão e repouso, da fuga e da repetição, das simultaneidades e das fragmentações. Para domesticar o sonoro, a música emerge com a pretensão de impor a ele um sentido, uma direção, uma história, uma lógica, um argumento, um tempo.

Na escola, a educação musical ainda tem apresentado, insistentemente, apenas o mundo gramatizado. Já escrito, textualizado, organizado, formatado, criado. Inúmeras vezes ela tem desconsiderado a relação entre o sonoro e o musical, que pode emergir na vivência de práticas criativas. A improvisação que propomos na presente investigação não oferece um modelo a seguir. Não se preocupa com a aquisição de um idioma ou padrão. Não pretende o desenvolvimento de uma técnica ou sonoridade para reproduzir corretamente um estilo ou artista. Os estilos e os artistas permaneceram porque foram capazes de romper com clichês anteriores e criar a sua linguagem. A poética da improvisação afirma a imaginação, persegue uma técnica para alcançar a necessidade expressiva desejada, proporciona ferramentas, sugere materiais, propõe exercicios brincantes. $\mathrm{Na}$ improvisação, o inesperado é fonte de inspiração (e não ameaça) e a irrepetivel condição do movimento.

Ao indicar que o relevante no ato de improvisar é justamente seu caráter irrepetível de ação disparada em tempo real, os estudos de Gainza (1983), Petruchelli (1998) e Alonso $(2008,2014)$ afirmam que improvisar envolve uma tomada de decisões no ato de fazer-se. "O improvisador tem que aprender a tomar decisões rápidas, a criar no momento, e compor sobre um acontecer que está sendo" (Alonso, 2008, p. 14). Essa prática envolve apreciar em ação, ou seja, exige um pensamento em ato. Aqui, "um erro 
pode ser unicamente um acerto involuntário" (Alonso, 2008, p. 61), ou o movimento para chegar à nova música, a outra técnica, a exercitar habilidades, estabelecer pontos de fuga, tempo e espaço de perder-se na fluência do fazer musical. Na experiência de improvisar, retira-se a música de seu lugar hierarquizado e competitivo de peça de consumo para conceituá-la como prática cotidiana e potência do humano.

Portanto, viver a poética da improvisação no Ateliê Poético da universidade compreende participar da experiência indizivel e inefável de produzir sentidos: "eu sabo porque sabo!", prática urgente e necessária na constituição da docência com crianças e na formação de professores. Ao colocar a música em estado de encontro, o grupo pode ensinar o corpo a fazer, estando disponível ao acesso e ressonância do coletivo, do cotidiano e do mundo. Tal atividade torna-se fundante para assumir a artesania do discurso sonoro como conquista de sua complexidade, ou melhor, "desfazer os nós que bloqueiam nossa capacidade inata de sentir e dar sentido" (Alonso, 2008, p. 98). Trata-se de alimentar a busca do gesto singular da docência, feita com as próprias mãos e com os próprios modos, que enriquecem e dinamizam os significados plurais. Modificam-no aqui e agora e lhes conferem argumento para o movimento.

\section{ATEliê PoÉtico}

O Ateliê Poético foi organizado na universidade como abordagem metodológica qualitativa da pesquisa de campo "Educação musical na formação de professores dos cursos de Graduação em Pedagogia gaúchos: processos de escuta e criação na experiência de barulhar" (Lino, 2017). Teve por objetivo garantir espaço para a escuta dos acadêmicos que pudesse indicar as práticas que informavam do trabalho da disciplina de educação musical na universidade. Definido nos propósitos do Grupo de Discussão Operativo (Gatti, 2016), o Ateliê Poético se configurou como estratégia metodológica pertinente para circunscrever a complexidade polissêmica investigada. Assim, a prática criativa da improvisação constituiu a forma de operação do Ateliê Poético, seguido de uma discussão sobre a experiência vivenciada, onde pesquisadora e participantes se envolveram de modo cooperativo e participativo durante o ano letivo de 2017 e 2018.

Utilizamos o propósito "Música em estado de encontro" para provocar a operação e discussão no Ateliê Poético, com o objetivo de aproximar os "referentes da ação docente" (Gatti, 2016, p. 288) tomados no efetivo cotidiano dos bancos universitários. A opção pelos referentes de ação docente, idealizado por Gatti (2016), constituiu categorização para movimentar o pensamento e destacar os elementos conceituais que emergem no tempo e no espaço do "saber da experiência" (Larossa, 2001). Isso porque compreendemos que a experiência proposta pela educadora se afasta 
[...] de certas interpretações que poderiam se ver associadas ao termo "padrões" (standards) em seu uso corrente em português, como um modelo ou exemplo a ser seguido. [...] [os referentes da ação docente] constituem critérios pelos quais possamos compreender e ajuizar, em uma perspectiva eminentemente formativa, diferentes tipos de atividades que compõem e informam o trabalho de professores, e não instrumentos por meio dos quais determinar as formas como as atividades docentes deveriam ser executadas e fundamentadas (Gatti, 2016, p. 288).

O Ateliê Poético não é espaço para ensinar música, mas lugar temporalizado da música em estado de encontro, modo de interlocução prática em torno da experiência de habitar a linguagem, improvisando. $\mathrm{O}$ importante é brincar com sons, desafiar os participantes a entrar no fluxo sonoro, para ressoar a experiência com educação musical na universidade. A prática criativa da improvisação envolveu simultaneamente as atividades lúdicas de escuta, convivio, seleção, apreciação, exploração, expressão, exposição, participação, isto é, brincar com sons para transformar sentidos em narrativas singulares. Os jogos de improvisação partiram da realidade cotidiana dos participantes, tentando, coletivamente, "entrar em relação" com os outros.

Para mobilizar os acadêmicos do curso de Licenciatura em Pedagogia a participar do Ateliê Poético, propusemos inicialmente a oficina "Improvisação Sonora" em espaço de interesse dos estudantes: o cofre da universidade. A atividade mobilizou também educadores musicais, instrumentistas e professores de educação infantil, que acabaram fazendo parte do grupo. A seleção dos participantes deu prioridade aos estudantes do curso de Licenciatura em Pedagogia (6) e aos professores de educação infantil formados em nossa universidade (5). O grupo investigado contemplou um número mínimo de 8 e máximo de 15 estudantes, que frequentaram o Ateliê Poético, participando de atividades de improvisação de maio a dezembro de 2017, realizadas em encontros quinzenais com duração de três horas. A participação dos estudantes na investigação esteve condicionada à frequência mínima de $75 \%$ no Ateliê Poético, da concordância do Termo de Consentimento Livre e Esclarecido e da Autorização de uso de imagens e dados digitais. Todos os encontros foram documentados em vídeo e/ou áudio pelos bolsistas do projeto e posteriormente organizados na forma de diário de campo. Os materiais coletados envolveram registros sonoros, musicais e discursivos da experiência vivida, incluindo depoimentos gravados, performances e documentos impressos pelos sujeitos (cartas, fotos, postagens no Facebook, WhatsApp, bilhetes).

A composição dos encontros no Ateliê Poético foi intencionalmente preparada com o objetivo de experimentar a improvisação, tendo o corpo como instrumento musical por excelência dessa prática criativa. Ao considerar com Alonso (2014) que a improvisação é o início de todo o 
processo criativo, essa investigação embasou as propostas conduzidas no Ateliê Poético nas ideias de Murray Schafer e Chefa Alonso. Trabalhamos com os princípios de educação sonora e criação musical idealizados por Schafer (1991) direcionados à aprendizagem da escuta e construção de relações criativas com as sonoridades da paisagem sonora. Consideramos que os jogos propostos por Schafer podem dar suporte aos professores músicos ou não músicos - e, quem sabe, animá-los a criar seus próprios exercícios para sublinhar que a criação não está separada da escuta, e, se "estamos condenados a ouvir" (Schafer, 2001), cabe uma educação sonora na prática docente.

De Chefa Alonso (2008) incorporamos a proposta da "improvisação livre", isto é, a composição em movimento. A improvisação livre é o resultado artístico, sempre único e irrepetível, de uma reunião de improvisadores. Uma improvisação que não está ligada a gêneros musicais específicos da música tradicional, mas à linguagem e à expressão pessoal, ao sentido de coletivo como motor de crescimento e à confiança no indivíduo para conjugar nosso espírito de igualitarismo (Alonso, 2008). Chefa Alonso considera a improvisação livre como atividade própria da vida comum. A saxofonista destaca que a força expressiva dessa prática criativa coloca em jogo, de forma poética, modos de se relacionar com o mundo enquanto comunicação e acontecimento compartilhado. Isso porque a improvisação pode reverberar os rituais cotidianos, o desfrute da natureza, bem como as formas de trabalho, jogos sociais e culturais da sociedade. Chefa afirma que, como linguagem da liberdade, a improvisação tem a finalidade de sair da convenção porque é uma ferramenta para facilitar a capacidade de se mover. Porém Alonso (2008, p. 13) alerta: "A liberdade é exigente e tem suas regras: temos que ouvir o outro, temos que senti-lo". "Improvisar não é tocar qualquer coisa" (Alonso, 2014, p. 29). Para improvisar, temos que escutar e dar espaço para os participantes do grupo entrarem em relação. Temos que ser curiosos, estar em contínua investigação (Alonso, 2008).

Neste contexto, dividimos a experiência de improvisar em exercícios musicais, isto é, consignas propostas com materiais e estruturas sonoras ou musicais e extramusicais, ou seja, consignas desencadeadas a partir de uma situação corporal, afetiva, social, cultural. Quanto à dinâmica de trabalho, a improvisação foi realizada tanto de forma individual quanto grupal. Convidamos os participantes a iniciarem uma conversa com sons, e, à medida que o grupo firmava vínculo afetivo com os colegas, a improvisação em pequenos grupos também emergia. Então as parcerias, os pequenos ostinattos, as justaposições contrapontísticas e a orquestra de improvisadores ressoavam no grupo. Da mesma forma, buscamos oferecer a exploração de diferentes materialidades no ato de improvisar: a percussão corporal, a paisagem sonora, os objetos sonoros, os espaços arquitetônicos habitados. 
Os integrantes do Ateliê Poético participaram de dois concertos-oficinas e uma instalação-performance. A escolha dos concertos-oficinas buscou valorizar os trabalhos autorais desenvolvidos em nossa cidade nos quais a improvisação fazia parte da performance artística. Sendo assim, selecionamos o Grupo Upa: grupo vocal que, em seus concertos, convida o público a compor uma peça ao vivo no coletivo. Do mesmo modo, o concerto-oficina Mais Tambor - Menos Motor, ministrado por Richard Serraria, convidou o público a conhecer e tocar o sopapo, único tambor tipicamente gaúcho, reconhecendo sua história, toque e criando em performance uma orquestra de tambores.

Improvisar na instalação-performance Húmus la piel no calla envolveu os estudantes do Ateliê Poético intensamente. Conduzida pela artista plástica argentina Teresa Peneda, a obra fez parte da BienalSur (Bienal Internacional de Arte Contemporânea da América do Sul). Teresa Peneda convidou os estudantes a pisarem no mapa da América do Sul, projetado em tamanho ampliado no piso do Salão de Festas da Reitoria da UFRGS. Ao problematizar o conceito de território e mapa, a artista convidou os acadêmicos a trazerem um objeto sonoro. Escutou a expressão oral ou instrumental dos participantes ao questionamento: Quem somos? Onde queremos estar? Inicialmente o grupo improvisou de forma individual, movimentando-se no espaço da instalação, e, à medida que a conversação se estabeleceu, a criação emergiu coletivamente. A atividade implicou grande ressonância no grupo, mobilizando-os a criar, ainda no final do ano 2017, a instalação "Jardim Sonoro", nossa primeira produção em Arte Sonora, ${ }^{3}$ oficialmente inaugurada na "Mostra Pedagógica da UFRGS" (Faced, 2017).

A avaliação e o encerramento das atividades no Ateliê Poético, em dezembro de 2017, envolveram a iniciativa dos participantes em habitar a escola de educação infantil com outras instalações sonoras. Formamos um grupo de estudo e nos reunimos para improvisar mensalmente, durante 4 horas, de maio a dezembro de 2018. O intuito do grupo se concentrava em interrogar, no cotidiano da educação infantil, práticas centradas, quase que exclusivamente, na imitação vocal de repertório canonizado à infância, desconsiderando os processos de escuta e criação envolvidos na improvisação.

\footnotetext{
3 Arte Sonora, uma produção artística que ocorre em conexão com a construção de seu próprio espaço de existência. Surgida em contraponto à paisagem paralisada no quadro do museu, a Arte Sonora explora novos suportes artísticos buscando envolver o espectador no sentido de torná-lo ativo. Nesse sentido, a arte sonora nega a voz passiva contemplativa do espectador, convidando-o a participar da obra de arte porque produz uma interferência em sua paisagem. A diversidade de abordagens do espaço e do tempo abrigadas no conceito de Arte Sonora alcança diferentes gêneros, mas boa parte de suas produções se realiza na forma de Instalações Sonoras e Esculturas Sonoras. Na Arte Sonora, o som não necessita estar preso ao encadeamento temporal, ele une outras fronteiras, aproximando-se de distintos materiais, como cor, luz, objeto, forma, porque é um processo híbrido no qual som, imagem, espaço e tempo se interpõem.
} 
Criar, produzir e desenvolver instalações e miniaturas sonoras revelouse prática formativa na organização do grupo de estudo em 2018. Inspirados nas instalações experimentadas, surgiram propostas para exploração da paisagem sonora interna e externa do ambiente escolar e de suas materialidades. Organizamos diferentes séries de miniaturas sonoras com materiais sustentáveis do cotidiano (bolas, cápsulas, cadeiras, canos, utensílios de cozinha etc.) propícias à manipulação, isto é, ao barulhar das crianças. Também idealizamos seis instalações sonoras, nomeadas: Caixa de Som, Série de Tambores, Cápsulas Sonoras, Cortinas Daqui, On-Off, Jardim Sonoro. Para registrar a lutheria das materialidades selecionadas, organizamos um caderno digital nomeado Libretos de Criação e um documentário intitulado Idiofones. Ao funcionar como registro pormenorizado do estudo realizado, os Libretos de Criação garantiram espaço de aperfeiçoamento e aprendizagem compartilhada à formação docente. Tempo de conversação, sintonia e poética, ou melhor, de viver o exercício de improvisar com professores e crianças na escola pública.

Portanto, a experiência de improvisação sonora do Ateliê Poético intensificou os processos de escuta e criação coletiva dos participantes, mobilizando-os a movimentar o conceito de som-ruído-silêncio-música. Todos afirmam participar pela primeira vez da ação de improvisar na universidade e sublinham a potência impar dessa prática criativa na escola pelo protagonismo compartilhado que outorga. Os estudantes ainda destacam que a poética da improvisação ensina o corpo a aprender de ouvido e inventar modos de tocar no coletivo.

\section{APRENDER DE OUVIDO}

Ao compor intencionalmente encontros para improvisar no Ateliê Poético, proporcionamos aos acadêmicos, educadores e instrumentistas a experiência de participar de interações e brincadeiras que ampliassem o alcance da educação musical na formação de professores. Ao oferecer um tempo-espaço propício à improvisação, conseguimos resgatar a dimensão lúdica da música implicada no ato simultaneamente solidário e solitário de o corpo ter que aprender a engendrar ações no mundo para compartilhar sentidos no coletivo. Nessa prática criativa, "aprender de ouvido" (Lino, 2017, p. 56) é potência desencadeada àqueles que se dispõem a tocar, barulhar, experimentar miniaturas sonoras, incorporar jogos e instalações, lançar-se à experiência do fazer brincante que se arrisca a entrar em sintonia porque disposto à escuta.

Sem um roteiro a cumprir, o tempo-espaço de improvisar exige do professor preparação:

Sim!!!, temos que mergulhar o ouvido na paisagem sonora escolar e nas materialidades que o cotidiano apresenta. Aprendemos de ouvido a combinar sons, encontrar territórios 
de silêncio e a começar uma conversa. Entrar em sintonia, ouvir e identificar o assobio dos passarinhos do pátio [...]. Localizamos de ouvido os utensílios sonoros e musicais para barulhar. E... de ouvido tocamos, sem ensaio prévio (Lino, 2017, p. 12).

Os participantes do Ateliê Poético insistem em afirmar que a improvisação in-corpo-ra um aprender de ouvido e destacam que, por se constituir numa atividade fundamentalmente coletiva e cotidiana, essa prática criativa prepara e ensaia o inesperado: ação fundante do saber docente. Consideram, com Chefa Alonso (2014), que a improvisação pode educar à exploração e negociação de outras formas de relações pessoais que não estejam embasadas na hierarquia e na competitividade, ainda muito presentes na rotina escolar. A improvisação convida os participantes a tocar, "um preparar-se para estar preparado. Preparar-se para habitar o presente no presente". Deleuze insiste que preparar não é planejar:

[...] o que faz do professor um professor não é o jeito de dar aula. Há várias formas de fazê-lo, mas a forma de se preparar para estar na sala de aula [...]. Uma aula é ensaiada. É como no teatro e nas cançonetas, há ensaios. Se não tivermos ensaiado o bastante, não estaremos inspirados [...], é preciso estar totalmente impregnado do assunto e amar o assunto do qual falamos. Isso não acontece sozinho. É preciso ensaiar na própria cabeça, encontrar o ponto [...], é preciso encontrar [...] (Deleuze, 1994, p. 60).

Desta forma, a experiência de colocar a música em estado de encontro, improvisando, pôde movimentar a reflexão intensa da educação musical na formação de professores. Para os pedagogos, a investigação sublinhou a necessidade urgente de também considerar a improvisação como atividade constituidora de fazeres e saberes musicais no cotidiano da sala de aula. Participando da experiência de improvisar, os pedagogos puderam compreender que a música é o jogo sonoro entre som e ruído, organizado pelo humano. Assim, ampliaram seu conceito de música, ainda fixado na repetição interpretativa vocal de canções na rodinha (Pires, 2006). A participação no Ateliê Poético fez com que emergissem as habilidades de interpretar, executar, apreciar, improvisar e compor como expressão integrada do fazer musical que não pretende hierarquizar ou escolher uma forma de viver a experiência musical, mas que se nutre da pluralidade de ações para provocar interrogações no/do discurso musical, ampliando outras buscas conceituais.

Os participantes do Ateliê Poético inúmeras vezes afirmam que consideravam a música uma "praia de poucos, dos talentosos, dos criadores, [...]. Ao tocar, entendi que a composição é para todos, todos somos musicais, basta começar!" (Lino, 2017, p. 32). Ao destacar que em sua formação docente poucas vezes "ensaiaram improvisações", os 
acadêmicos declaram a importância da formação docente na área para ensinar o corpo a aprender de ouvido, a escutar o ruído, a paisagem sonora, o silêncio. É claro que o corpo precisa estar disposto a acolher as sonoridades em movimento, emergentes na vida cotidiana.

Tal experiência

[...] passa por um determinado encontro com e no mundo. Um encontro que busca na presença do presente, aqui e agora, uma densidade existencial capaz de deslocar as prévias determinações para os acasos indeterminados pelos interstícios dos instantes da ação pedagógica. Que seja uma experiência possivel, ao mesmo tempo, de produzir uma presença não reduzida à simplificação de significados pela instrumentalidade de uma precoce escolarização. Que seja uma experiência de linguagem como gesto que reconhece a potência em que se apoia a linguagem, um retorno às infâncias do pensamento, no qual a linguagem recupera seu caráter gestual de meio puro, isto é, desvinculado de qualquer finalidade (ou de sua instrumentalidade) (Richter; Berle, 2015, p. 1039).

Instrumentalizar os alunos de educação infantil nas aulas de música a entoar o nome das notas da escala musical em ordem crescente; ou solicitar que nomeiem o timbre de determinado instrumento musical; e/ou ainda que descrevam a classificação da altura de um som, não significa que estamos iniciando sua musicalização. A lista de conteúdos e objetivos a prescrever é grande, a oferta de receitas e didáticas enlatadas pode estar disponivel num clique. Porém, a compreensão da educação musical a partir da prática criativa da improvisação pode contribuir para que possamos afastá-la da simplificação dos significados para sublinhar presença, porque a música é gesto do corpo no mundo.

A prática criativa da improvisação é, pois, composição em movimento, ensaio de dissonâncias e aleatoriedades do mundo sonoro e musical que cria e recompila materiais e ferramentas para sublinhar a música em estado de encontro. Conexão coletiva com a maneira de fazer (didática), com o assunto a perseguir (conteúdo), com a ferramenta necessária para complexificar o encontro (técnica). Longe de ser considerada mera expressão da espontaneidade, a improvisação pode habitar a formação de professores na universidade, exercitando os processos de escuta e criação para compor a complexidade do discurso musical.

$\mathrm{Na}$ tentativa de narrar as experiências vivenciadas no Ateliê Poético, os acadêmicos decidem indicar o que ela não é. Improvisar

[...] não tem receita. Não tem pensamento, nem obrigação. Não pode parar, tem que pegar o trem e seguir. Não tem corrida, não tem pressa, não tem ficar parado. É um tempo de muito cansaço, não tem mensagem. Não tem ficar de fora! Não pode desconfiar! Não tem 
combinação anterior, é todo mundo junto! [...], não ao mesmo tempo, mas conectados (Lino, 2017, p. 64).

Ao optar por relatar o revés da improvisação, a memória afetiva de um modo de fazer experimentado na universidade invade a performance dos participantes, porque tatuagem do "feito em casa, na sala de aula, no pedacinho da escola" (Lino, 2017, p. 23). As improvisações revelam as materialidades sonoras com as quais têm familiaridade, "aprendimentos" de um corpo sensivel, constituído temporalmente com os outros no mundo. Por essa razão, vimos emergir memórias do pátio de suas casas, da escola que frequentavam, ou de práticas cotidianas. Fomos compreendendo que "aprender supõe coisas a fazer e não a descobrir: somos inseparáveis do mundo do qual fazemos parte e o qual podemos transformar" (Richter, 2015, p. 250). Aqui a repetição emerge com força potente e esculpe um jeito de fazer que se relaciona diretamente às vivências anteriores de cada participante. Isso porque, como afirma Gainza (1983, p. 15), a improvisação é lugar de exposição, possibilidade de externalizar materiais auditivos internalizados.

Ao inaugurar sentidos, o ato de improvisar teve como personagem de destaque o ruído. Como território que escapa ao controle, o ruído aparece como elemento de disposição à ação. Os participantes do Ateliê Poético parecem confirmar as palavras de Attali (1997, p. 9): “com o ruído nasce a desordem e seu oposto: o mundo". Ao tomar o corpo como materialidade fundante da improvisação, os participantes entendem que é o apelo à ordem que faz da música esta organização concebida intencionalmente pelo humano de sons e silêncios - o que insistentemente afirmavam desconhecer. Assim, consideram que a improvisação contribui para a descolonização do repertório sacralizado à educação musical na infância.

Portanto, quando se experimenta a prática criativa da improvisação, "se produz emoção!" (Lino, 2017, p. 4) para afirmar, sem rodeios, "eu também sou musical!" (Lino, 2017, p. 4). Eu sei tocar porque ensinei o meu corpo a conversar, a entrar em sintonia, a barulhar, a manter o fluxo sonoro no coletivo. “Eu sabo porque sabo!" Ensinei meu corpo a aprender de ouvido, brincando. A improvisação pode movimentar a docência para os trânsitos plurais que se desejam sensivelmente modificar. Como prática criativa lúdica e afetiva, a improvisação é a marca de todo gesto humano que toca para narrar parcerias com o mundo. $\mathrm{O}$ ato de improvisar pode aproximar e intensificar os processos lúdicos de escuta e criação em educação musical, possibilidade de conversação e exercício do saber docente.

\section{REFERENCIAS}

AGAMBEN, Giorgio. Infancia e Historia: ensayo sobre la destrucción de la experiência. 5. ed. Buenos Aires: Adriana Hidalgo Editora, 2011 [2005]. 
ALONSO, Chefa. Enseñanza y Aprendizaje de la Improvisación Libre: propuestas y reflexiones. Madrid: Editorial Alpuerto, 2014.

Improvisación Libre: la composición en movimiento. España: Dos Acordes, 2008.

ARENDT, Hannah. A condição humana. Tradução de Roberto Raposo; posfácio Celso Lafer. 10. ed. Rio de Janeiro: Forense Universitária, 2005.

. A dignidade da política. Tradução de Antônio Abranches e Helena Martins. Rio de Janeiro: Relume Dumará, 2002.

ATTALI, Jacques. Bruits: essai sur l'économie politique de la musique. Paris: Presses Universitaires de France, 1977.

BELlOQUIO, Claudia Ribeiro (Org.). Educação Musical e Unidocência: pesquisas, narrativas e modos de ser professor de referência. Porto Alegre: Sulina, 2017.

BRASIL. Conselho Nacional de Educação. Câmara de Educação Básica. Resolução n. 5, de 17 de dezembro de 2009. Fixa as Diretrizes Curriculares Nacionais para a Educação Infantil. Brasília: CNE/CEB, 2009.

. Ministério da Educação. Base Nacional Comum Curricular. MEC.

Brasília, DF, 2017. Disponível em:

http:/ / basenacionalcomum.mec.gov.br/wp-

content/uploads/2017/12/BNCC_19mar2018_versaofinal.pdf. Acesso em: 30 mar. 2018.

. Conselho Nacional de Educação. Conselho Pleno. Resolução n.1, de 1 de julho 2015. Institui as Diretrizes Curriculares Nacionais para o Curso de Graduação em Pedagogia, licenciatura. Disponível em:

<http://portal.mec.gov.br/>. Acesso em: 18 set. 2016.

CAGE, John. Musicage: palavras. John Cage em conversação com Joan Retallack. Rio de Janeiro: Numa, 2015.

DELEUZE, Gilles. Abecedário. Disponivel em: http://escolanomade.org/wpcontent/downloads/deleuze-o-abecedario.pdf. Acesso em: 30 mar. 2018.

FACED. Mostra Pedagógica da FACED UFRGS. Seminário de 0 a 3 anos. Registros dos encontros com as crianças. Power Point produzido por Dulcimarta Lemos Lino, dez 2017. FACED/UFRGS, DVD.

FIGUEIREDO, Sérgio Luiz Ferreira de. Educação musical e legislação educacional. Salto Para o Futuro, ano XXI, Boletim 8, jun. 2011. MEC.

FONTERRADA, Marisa Trench de O. De tramas e fios: um ensaio sobre música e educação. São Paulo: Editora da Unesp, 2008. 
. Ciranda de sons: práticas criativas em educação musical. São Paulo: Editora da Unesp, 2015.

FREGA, Ana Lucia. Metodología Comparada de la Educación Musical. Buenos Aires: Collegium Musicum de Buenos Aires, 1997.

GAINZA, Violeta Hemsy de. La improvisación musical. Ricordi: Buenos Aires, 1983.

GATTI, Bernadete; SILVA, Vandré Gomes; ALMEIDA, Patricia Cristina Albieri. Referentes e critérios para a ação docente. Cadernos de Pesquisa, v. 46, n. 160, p. 286-311, abr./jun. 2016.

LAROSSA, Jorge. Notas sobre a experiência e o saber da experiência. Revista Brasileira de Educação, n. 19, p. 20-28, jan./abr. 2002.

LINO, Dulcimarta Lemos. A casa dos Soares. In: GOBBI, Valeria (Org.). Questões de Música. Passo Fundo: Editora da Universidade de Passo Fundo, 2011. p. 49-75.

. Educação Musical na formação de professores dos Cursos de Graduação em Pedagogia: processos de escuta e criação na experiência de barulhar. Pesquisa em andamento. FACED/UFRGS, 2017.

MAFFIOLETTI, Leda de Albuquerque. Práticas musicais na escola infantil. In: CRAIDY, Carmem Maria; KAERCHER, Gládis Elise (Orgs.). Educação Infantil pra que te quero? Porto Alegre: Universidade Federal do Rio Grande do Sul, 1998. p.111-122.

MATEIRO, Teresa; ILARI, B. (Orgs.). Pedagogias em educação musical. Curitiba: Ibpex, 2011. (Série Educação Musical).

Pedagogias brasileiras em educação musical. Curitiba: InterSaberes, 2016. (Série Educação Musical).

PETRUCHELLI, Daniel. Teoria de la Improvisación en Música. Montevideo: Centro de Difusión del Libro, 1998.

PIRES, Maria Cristina. O som como linguagem e manifestação da pequena infância. 2006. 107f. Dissertação (Mestrado) - Faculdade de Educação, Universidade Estadual de Campinas, 2006.

RICHTER, Sandra Simonis; BERLE, Simone. Pedagogia como Gesto Poético de Linguagem. Educação e Realidade, v. 40, p. 1027-1043, 2015.

SCHAFER, Murray. O ouvido pensante. São Paulo: Unesp, 1991.

WISNIK, José Miguel. O som e o sentido: uma outra história das músicas. São Paulo: Companhia das Letras, 1989. 
Duclimarta Lemos Lino é professora da Universidade Federal do Rio Grande do Sul (UFRGS) na Faculdade de Educação, Departamento de Estudos Especializados, na área Educação Infantil. Doutora em Educação pela Universidade Federal do Rio Grande do Sul (UFRGS), Mestre em Educação pela Universidade Federal do Rio Grande do Sul (UFRGS) e Licenciada em Educação Artística: Habilitação em Música pela Universidade Federal do Rio Grande do Sul (UFRGS). Fundadora e pesquisadora do Coletivo do Espaço de Criação Musical, escola de música que criou em 1993 para experimentar a poética do barulhar e os tempos e espaços coletivos de viver a música brasileira. Pianista e diretora musical. Coordenadora do PIA: Núcleo Itinerante de MPB da Faculdade de Educação da UFRGS, grupo musical que se dedica a realizar concertos e oficinas em escolas públicas de educação infantil. Dirige o Grupo de Pesquisa Escuta Poética (FACED/UFRGS). Desenvolve projeto de pesquisa em parceria com o Pós-Graduação em Educação da Universidade de Santa Cruz do Sul (UNISC): "Experiencia poética e docência na Educação Básica: linguagem, intercorporalidade e mundo". https://orcid.org/0000-0002-1195-1683

Gabriel do Nascimento Dornelles é estudante do curso de Licenciatura em Pedagogia da Faculdade de Educação da UFRGS. Professor da rede particular de ensino e músico. Pesquisador do Projeto de Pesquisa Educação Musical na formação de professores dos cursos de Graduação em Pedagogia gaúchos na FACED/UFRGS. Participa do Curso de Extensão Pia: Concertos e Oficinas. É integrante do Pia: Núcleo Itinerante de MPB da FACED/UFRGS coordenado pela professora Dulcimarta Lemos Lino. https://orcid.org/00000003-1471-7435 